\title{
RELATIONSHIP BETWEEN RICE RESIDUE BURNING AND INCREASING AIR POLLUTION IN NORTH-WEST INDIA
}

\author{
Sheetal Bhadauriya ${ }^{1,2}$, Navendu Chaudhary ${ }^{2}$, S. Mamatha ${ }^{1}$ and S. S Ray ${ }^{1 *}$ \\ ${ }^{1}$ Mahalanobis National Crop Forecast Centre, IARI Campus, New Delhi, India - (mamatha, shibendu). ncfc@ nic.in \\ ${ }^{2}$ Symbiosis Institute of Geoinformatics, Symbiosis International (Deemed) University, Pune, India - \\ sheetal.bhadauriya@gmail.com, navendu@sig.ac.in \\ Commission III, WG III/10 \\ *Corresponding Author
}

KEY WORDS: Rice, Residue Burning, Fire Counts, Environmental Pollution, Aerosol Optical Depth, Dust Storms

\begin{abstract}
:
Punjab and Haryana are two major Rice-producing states of India. They generate high amount of rice residue every year and these residues are burnt in the months of October and November to clear the fields for the next sowing, i.e. Wheat. Residue burning in these two states is considered to be a major factor for the pollution conditions persisting in Delhi, the capital of the country, during October and November. In this study, we aim to analyse the role of stubble burning on Pollution. The approach aimed at a) Determination of rice straw contingent to open burning in the states of Punjab and Haryana, b) Determine and quantify the air pollutant emissions from rice residue contingent to open burning and c) Compare them with the air pollution of Delhi. Also, in order to analyse the various reasons for the increasing pollution in Delhi, Aerosol Parameters like Aerosol Optical Depth, Angstrom Exponent and Single Scattering Albedo were also studied along with auxiliary data like Temperature, Wind Directions, Wind Trajectories, MODIS Fire Counts and CPCB Pollution Data. In this study, we found that not only residue burnings of Punjab and Haryana, but also dust storms from far beyond these states influence the pollution levels in Delhi, especially in the case of Particulate Matter less than 10.
\end{abstract}

\section{INTRODUCTION}

Stubble burning is a common practice in many rice growing regions of India. Every year, tonnes of rice are produced in the states of Punjab and Haryana. Eighteen districts of Haryana produce rice out of which seven are in high productivity group of India, whereas most of the districts of Punjab produce rice and all of them are in high-productivity group (Directorate of Rice). The rice is harvested in the months of October (Beginning) or November (End), for the both the states. Intensive wheat cultivation is also carried on the same fields/area. The sowing period of the wheat begins in November/December depending upon when the rice/paddy is harvested. This creates a pressure on the farmers as there is a very a narrow window to clear the field after harvesting rice and sowing wheat as the next crop. The farmers use machinery (combines) to harvest the crop, hence it leaves the stubble/residue in the field, and it is then burnt openly, emitting tonnes of pollutants. Streets et al. (2003) estimated that on annual average basis more than one-third of biomass burnt in Asia comes from agricultural-residue burning.

Various researchers have studied the impact of biomass burning on air pollution due to emission of trace gases and aerosols (Andreae and Merlet, 2001; Kaskaotis, et al. 2014). According to Kaskaotis et al. (2014), aerosols over India show a mixture of anthropogenic emissions, smoke from seasonal forest fires or crop residue burning, long-range transported or even locally produced dust, and particles of marine origin during the summer monsoon.

In this context, the residue burning of Punjab and Haryana was assessed vis-à-vis the air pollution in the neighbouring capital city, Delhi. Other contributing factors for Air pollution, such as dust storm, wind pattern and temperature were also studied.

\section{MATERIALS AND METHODS}

\subsection{Study Area}

The study was conducted for the states of Punjab $\left(30^{\circ} 47^{\prime} 24^{\prime \prime}\right.$ $\left.\mathrm{N}, 75^{\circ} 50^{\prime} 24^{\prime \prime} \mathrm{E}\right)$ and Haryana ( $\left.30^{\circ} 47^{\prime} 24^{\prime \prime} \mathrm{N}, 75^{\circ} 50^{\prime} 24^{\prime \prime} \mathrm{E}\right)$ in North-West India. These two states produce highest amount of rice-residue. The impact of open burning of these rice residues are studied for the National Capital Territory of Delhi $\left(28^{\circ} 36^{\prime}\right.$ $36^{\prime \prime} \mathrm{N}, 77^{\circ} 13^{\prime} 48^{\prime \prime} \mathrm{E}$ ).

\subsection{Data Used}

The data for production of rice was collected from the FASAL project (Ray \& Neetu, 2017). The production has been derived from the satellite-based area assessment and model-based yield assessment (Jain et al., 2019). This data was collected districtwise for the states of Punjab and Haryana for the year 2014 to 2017. The pollution data for the state of Delhi was collected from the Central Pollution Control Board (CPCB) to compare with the calculated emissions from open field burning in Punjab and Haryana. The data on fire counts was downloaded for the period $1^{\text {st }}$ January 2014 to $31^{\text {st }}$ December 2017 from Moderate Resolution Imaging Spectrometer Collection 6 (MODIS C6), both aqua and terra with resolution of $1 \mathrm{~km}$.

The levels of pollution were studied according to the Aerosol Properties like the Aerosol Optical Depth (AOD), Single Scattering Albedo (SSA) and Angstrom Exponent (AE). AOD is the degree upto which aerosols prevent the transmission of light by absorption or scattering of light. The aerosol optical depth or optical thickness $(\tau)$ is defined as the integrated extinction coefficient over a vertical column of unit cross section. Single-scattering albedo (SSA) is the ratio of scattering efficiency to total extinction efficiency (which is also termed "attenuance", a sum of scattering and absorption). Most often, it 
is defined for small-particle scattering of electromagnetic waves. Lastly, the value of the Angstrom exponent is also a qualitative indicator of aerosol particle size. Hence, more is the exponent, dominance of fine particles and vice versa. These parameters help to understand the nature of the pollutant in the air (Montilla et al., 2011). Due to the large spatial and temporal variability of aerosols, satellite remote sensing provides the most reliable information about aerosol distributions (Ramanathan et al., 2001)

The meteorological data like Wind Direction, Wind Speed, temperature, Rainfall were downloaded from MOSDAC (Meteorological and Oceanographic Satellite Data Archival Centre), of Indian Space Research Organisation and from IMD (Indian Meteorological Department). The Aerosol Parameters, to know the type of the particles in the air, were downloaded from the Giovanni, NASA (https://giovanni.gsfc.nasa.gov/giovanni/). The data, which was downloaded, was area averaged, as the grid of the Delhi is too small. The spatial resolution for each AOD and AE dataset is $1^{\circ}$. AOD daily data products from Terra and Aqua Deep Blue AOD, at $0.55 \mu \mathrm{m}$, (MYD08_D3_v6 and MOD08_D3_V6) were utilized in this study (Sharma \& Kulshrestha, 2014), For SSA, its $0.25^{\circ}$. The temporal resolution is of 1 day. The Wavelengths for SSA are $342.5 \mathrm{~nm}, 388 \mathrm{~nm}, 442 \mathrm{~nm}, 463 \mathrm{~nm}, 483 \mathrm{~nm}$. The wind trajectories were downloaded from NOAA's HYSPLIT Trajectory Model (Stein et al., 200. These trajectories are computed for $500 \mathrm{~m}$ of height and one week backward to know the source of the wind coming to Delhi.

\subsection{Methodology}

The approach aimed at various steps to reach the ultimate objective to ascertain the role of rice-residue open field burning in increasing pollution trend in Delhi is presented in figure 1.

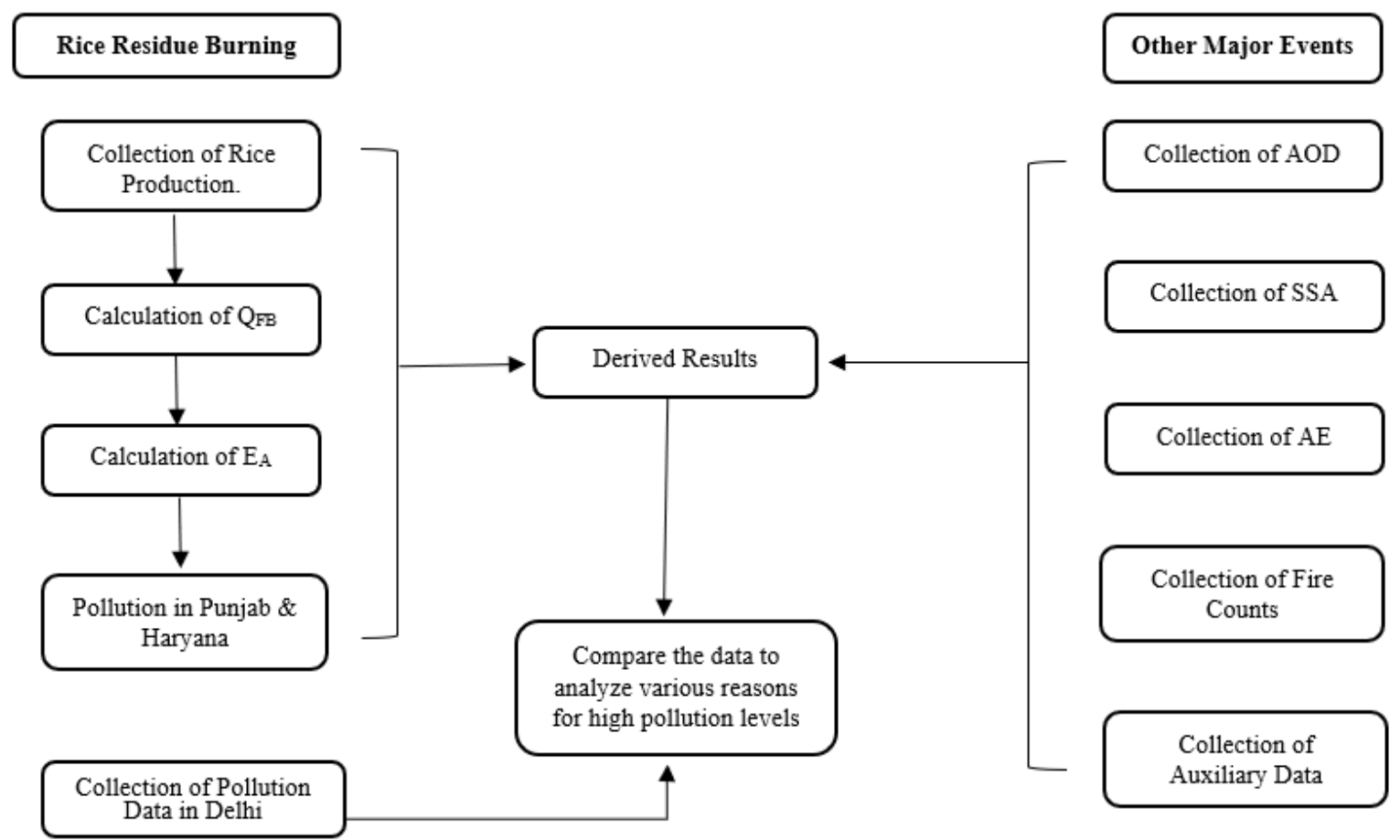

Figure 1: Methodology followed

2.3.1 Determination of Rice Residue: The total quantity of rice residue generated in the states of Punjab and Haryana was calculated using Residue to Grain Ratio (RGR) of 1.5 (Gupta et al., 2004; Sidhu et al., 1998). Using this value, the equation (1) was used to determine the quantity of rice residue that will be burned:

$$
Q_{F B}=P R \times Q_{P P} \times R G R
$$

Where, QFB is Quantity of Rice Straw subject to open field burning ( $\mathrm{t}$ of dry matter). PR is Production of rough rice $(1.5 \mathrm{x}$ Production of rice in tonnes) (Kumar, 2015), QPP is proportion of rice straw subject to open field burning (0.8) and RGR is 1.5:1.
2.3.2 Quantification of the emissions released from the residue: The approach is based on the methodology set by the Intergovernmental Panel on Climate Change (IPCC) guidelines 2006. This methodology was followed except for the step to quantify the amount of rice residue for burning $\left(\mathrm{Q}_{\mathrm{FB}}\right)$, where we used RGR ratio and the proportion of rice straw subject to open burning. In order to ascertain the amount of pollutants generated in the air, the emission factor (Ef) was used which was calculated according to the weight of the pollutant emitted per unit mass of dry fuel consumed. Equation (2) was used to quantify emissions from rice residue:

$$
\mathbf{E}_{\mathbf{a}}=\mathbf{Q}_{\mathrm{FB}} \times \mathbf{E f}_{\mathrm{a}} \times \mathbf{F}_{\mathbf{C O}}
$$

where, $a$ is Pollutant, $\mathrm{E}_{a}$ is Emission of $a$ in $\mathrm{gg} / \mathrm{year}, \mathrm{Q}_{\mathrm{FB}}$ is Quantity of Rice residue generated in gg/year. Efa is Emission Factor of $a$ in $\mathrm{g} / \mathrm{kg}$ of dry straw and FCO is combustion factor (0.80). Default values as per IPCC 2006 guidelines, (Volume 4, Table 2.6.) (Aalde et al., 2006) were used in this study. 
2.3.3 Air pollutants and Emissions factors: Open field burning is an uncontrolled combustion process during which species such as $\mathrm{CO}_{2}$, nitrous oxide $\left(\mathrm{N}_{2} \mathrm{O}\right), \mathrm{CH}_{4}, \mathrm{CO}$, nonmethane hydrocarbons ( $\mathrm{NMHC}$ ), $\mathrm{NO}_{x}, \mathrm{SO}_{2}$, particulate matter (PM) and few others are emitted (Gadde, 2009). In this study, due to unavailability of the pollution data of few years and few pollutants, only Sulphur Dioxide $\left(\mathrm{SO}_{2}\right)$, Nitrogen Dioxide $\left(\mathrm{NO}_{2}\right)$ and $\mathrm{PM}_{10}$ were considered for the study in Delhi. The emissions factors were taken from the literature (Gadde, 2009) (Table 1).

\begin{tabular}{|l|r|}
\hline Pollution Species & Emission Factor \\
\hline $\mathrm{CO}_{2}$ & 1460 \\
\hline $\mathrm{CH}_{4}$ & 1.2 \\
\hline $\mathrm{N}_{2} \mathrm{O}$ & 0.07 \\
\hline $\mathrm{PM}_{2.5}$ & 12.95 \\
\hline $\mathrm{PM}_{10}$ & 3.7 \\
\hline $\mathrm{CO}$ & 34.7 \\
\hline $\mathrm{NO}_{\mathrm{x}}$ & 3.10 \\
\hline $\mathrm{SO}_{2}$ & 2.0 \\
\hline
\end{tabular}

Table 1. Emission Factors (Source: Gadde, 2009)

\section{RESULTS AND DISCUSSION}

\subsection{Quantification of Emissions}

From the year 2014 to 2017, the state of Punjab alone generated total emissions (approx.) of 62,00,000 gg/yr, 67,00,000 gg/yr, $77,00,000 \mathrm{gg} / \mathrm{yr}$ and $72,00,000 \mathrm{gg} / \mathrm{yr}$ from open field burning. The state of Haryana emitted approximately. 21,00,000 gg/yr,
$23,00,000 \mathrm{gg} / \mathrm{yr}, 24,00,000 \mathrm{~s} \mathrm{gg} / \mathrm{yr}$ and 26,00,000 $\mathrm{gg} / \mathrm{yr}$ of pollutants, respectively, which is around one third of Punjab emissions, every year (Table 2). Thus, as compared to Haryana, Punjab is more pollution-producing state from rice residue.

\begin{tabular}{|c|r|r|}
\hline Year & $\begin{array}{c}\text { Punjab's Total } \\
\text { Emissions }(\mathrm{gg} / \mathrm{yr})\end{array}$ & $\begin{array}{c}\text { Haryana's Total } \\
\text { Emissions }(\mathrm{gg} / \mathrm{yr})\end{array}$ \\
\hline 2014 & $62,00,000$ & $21,00,000$ \\
\hline 2015 & $67,00,000$ & $23,00,000$ \\
\hline 2016 & $72,00,000$ & $24,00,000$ \\
\hline 2017 & $77,00,000$ & $26,00,000$ \\
\hline
\end{tabular}

Table 2: Total State Emissions from 2014 to 2017

\subsection{Comparison of the calculated Emissions of Punjab \& Haryana with Pollution Data of Delhi}

Figure 2 shows the comparative total emissions from 2014 to 2017 for the months of October to November. This include calculated emissions of Punjab and Haryana (gg/year) and pollution data of Delhi $\left(\mu \mathrm{g} / \mathrm{m}^{3}\right)$. It can be seen that the levels of Sulphur Dioxide have increased from 2014, as shown in figure 4 , as well as the calculated emissions also increased. For Nitrogen Oxides (figure 5), it may be noted that, the data included for Delhi was only for Nitrogen Dioxide, which is a part of Nitrogen Oxides. The pollution levels in Delhi were very high in 2016 as compared to calculated emissions. For $\mathrm{PM}_{10}$ the Delhi pollution was much higher than calculated emissions in all these years (figure 6). To know the cause of such deviations in pollutions, help from auxiliary data like MODIS Fire Counts and Meteorological Parameters and other factors that might be responsible, were taken into account to understand high level of pollution in Delhi.
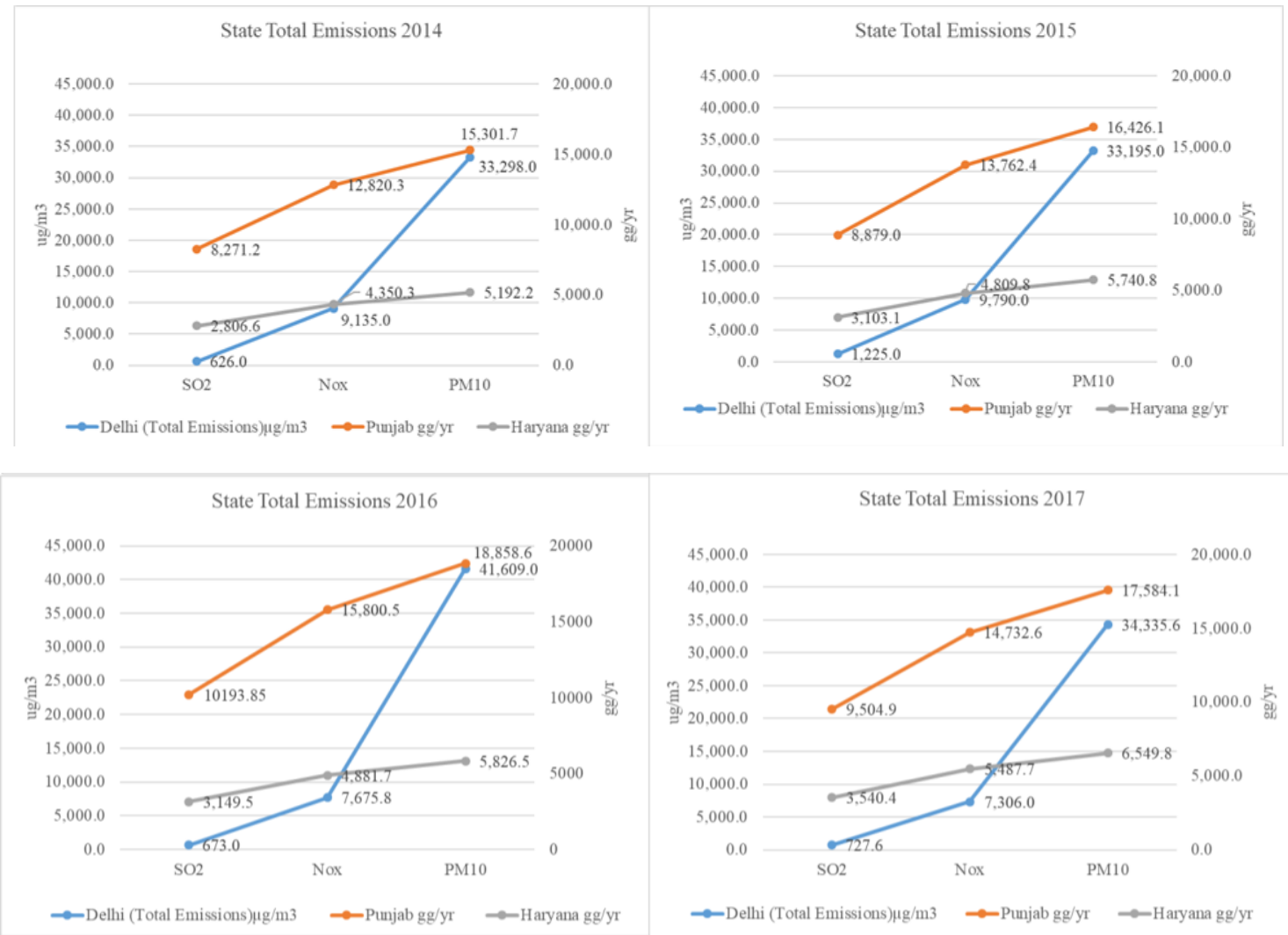

Figure 2: Comparison of total emissions from 2014 to 2017 


\subsection{Analysis of the deviation in Pollution Levels of Delhi}

To understand the deviation, various factors were studied in order to interpret the scenario. From the figure 3, we see that in every October to November, the fire counts increased as compared to whole year because of rice residue burning in Punjab and Haryana (combined). As compared to all the years, the 2016 had the highest number of total fire counts whereas 2017 had the lowest. We can understand the increase of pollution levels at that time of the year but to understand the situation better, interpolation of the pollution data for every year was done using kriging method, after collecting the pollution data from various Delhi pollution-monitoring stations.

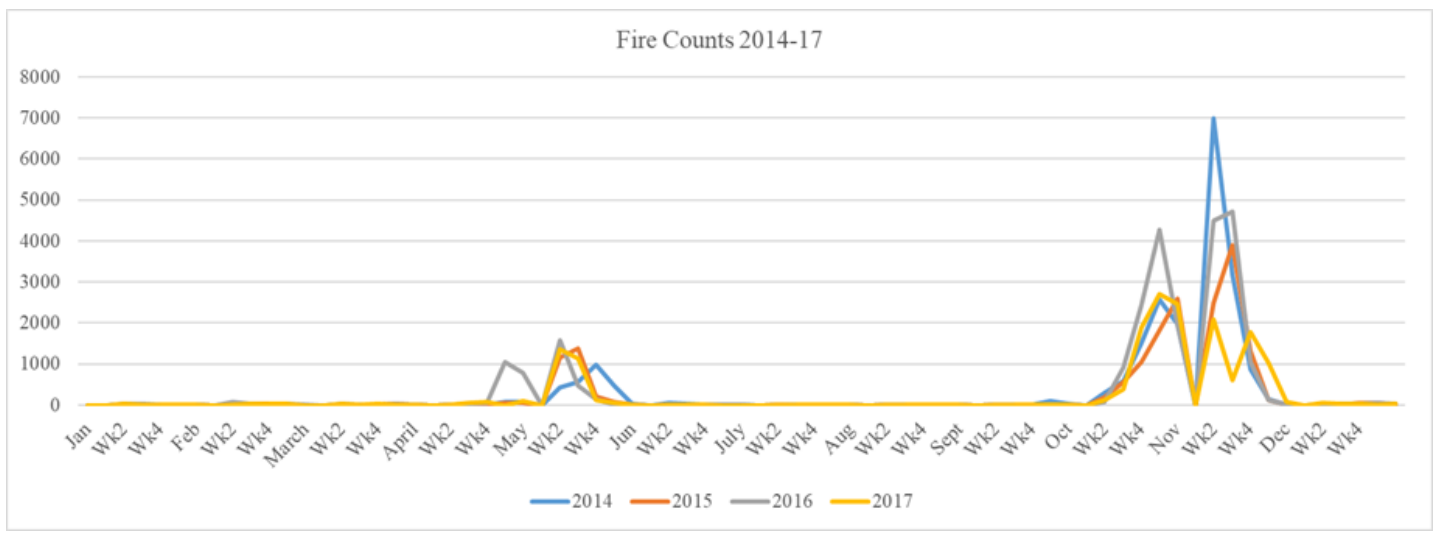

Figure 3: MODIS Fire Counts

From the year 2014 to 2017 , the $\mathrm{SO}_{2}$ levels increased rapidly in 2016 and then can be seen declining in 2017 (Figure 4). However, RK Puram (a place in Delhi) had the maximum $\mathrm{SO}_{2}$ Emissions of $30 \mu \mathrm{g} / \mathrm{m} 3$ in 2017.The Area of Anand Vihar and IGI throughout the years, received highest $\mathrm{SO}_{2}$ emissions, which may be attributed to high number of vehicles, resulting fuel combustions. For the case of 2016, the fire counts were high; also, the event of Diwali (an Indian festval, where people engage in bursting crackers and fireworks) caused the maximum (highest in all the years studied) emissions of Sulphur, which made the air toxic.
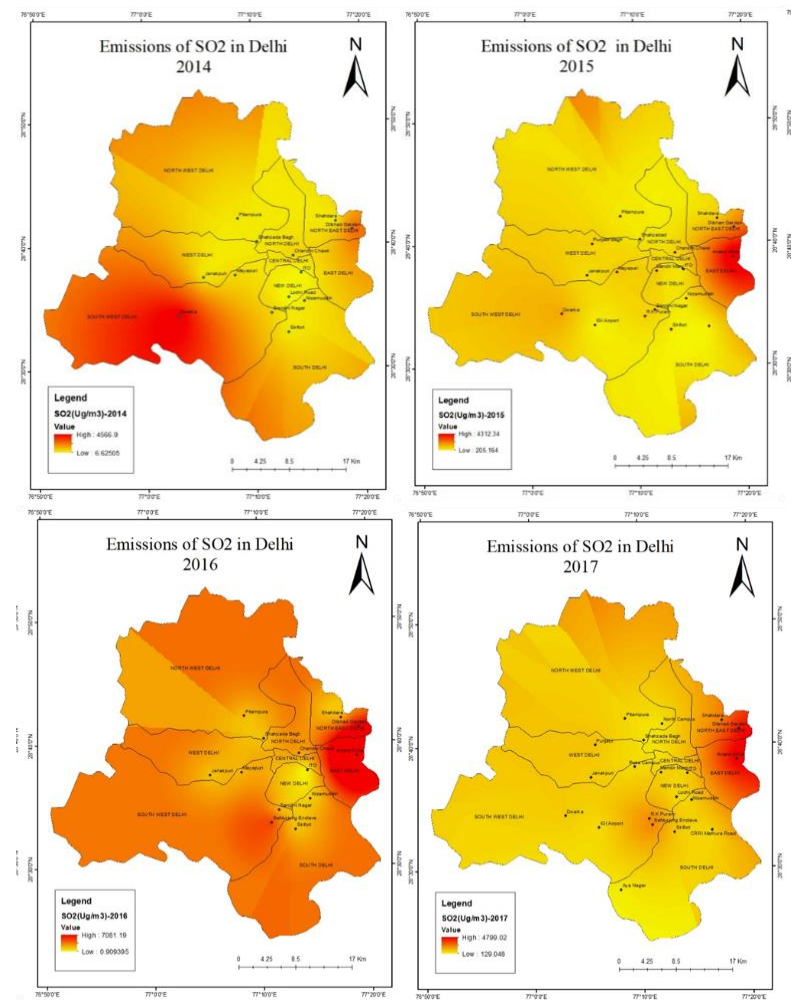

The levels for $\mathrm{NO}_{2}$ were higher than the ambient levels $(80$ $\mu \mathrm{g} / \mathrm{m}^{3}$ ) for the most period of the year. In urban outdoor air, the presence of $\mathrm{NO}_{2}$ is mainly due to traffic. Nitric oxide (NO), which is emitted by motor vehicles or other combustion processes, combines with oxygen in the atmosphere, producing $\mathrm{NO}_{2}$. Indoor $\mathrm{NO}_{2}$ is produced mainly by unvented heaters and gas stoves (Anonymous, 2018). The figure 5 shows the transition from increasing Nitrogen Dioxide levels then slight decline in 2016 and again increase in 2017.

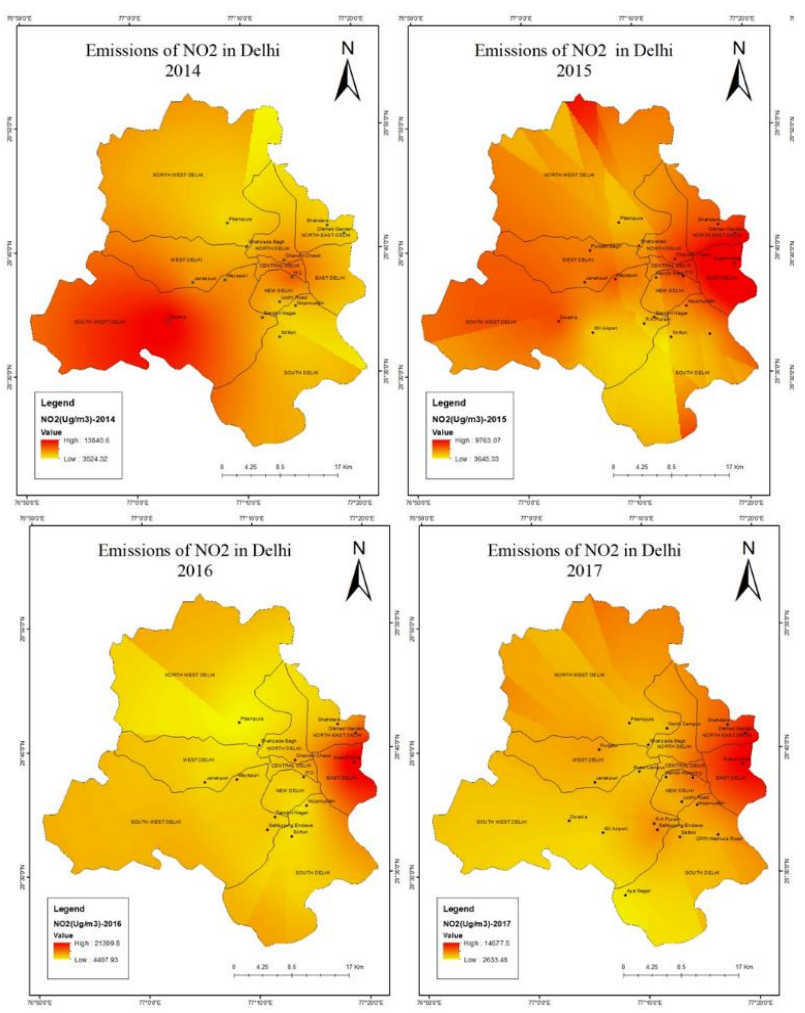

Figure 5: Trends of Nitrogen Dioxide in Delhi

Figure 4: Trends of Sulphur Dioxide in Delhi 
This was because to curb on the emissions from particulate matter less than 10 microns, which increases due to vehicles, the engine technology was changed and by the end of 2016, the engines burnt down the fuel less, which controlled the $\mathrm{PM}_{10}$ but the engines burnt the fuel at high temperature, which might have resulted more $\mathrm{NO}_{2}$. Hence, there is slight increase in $\mathrm{NO}_{2}$ in 2017. There can be other reasons for $\mathrm{NO}_{2}$ up and down trend, like burning fossils fuels, thermal power plants, etc.

Particulate Matter less than 10 (Fig 6) is caused by various factors. One cannot draw the possible concrete conclusions on the trends as it completely depended upon the atmospheric factors. It can be caused by natural reasons like Volcanoes, Dust Storms, Forest Fires, Tornadoes and Hurricanes or Man-Made reasons like Coal, Oil and Wood Combustions, Construction, Demolition, Road Dust, Power plants, Industrial and agricultural reasons etc.
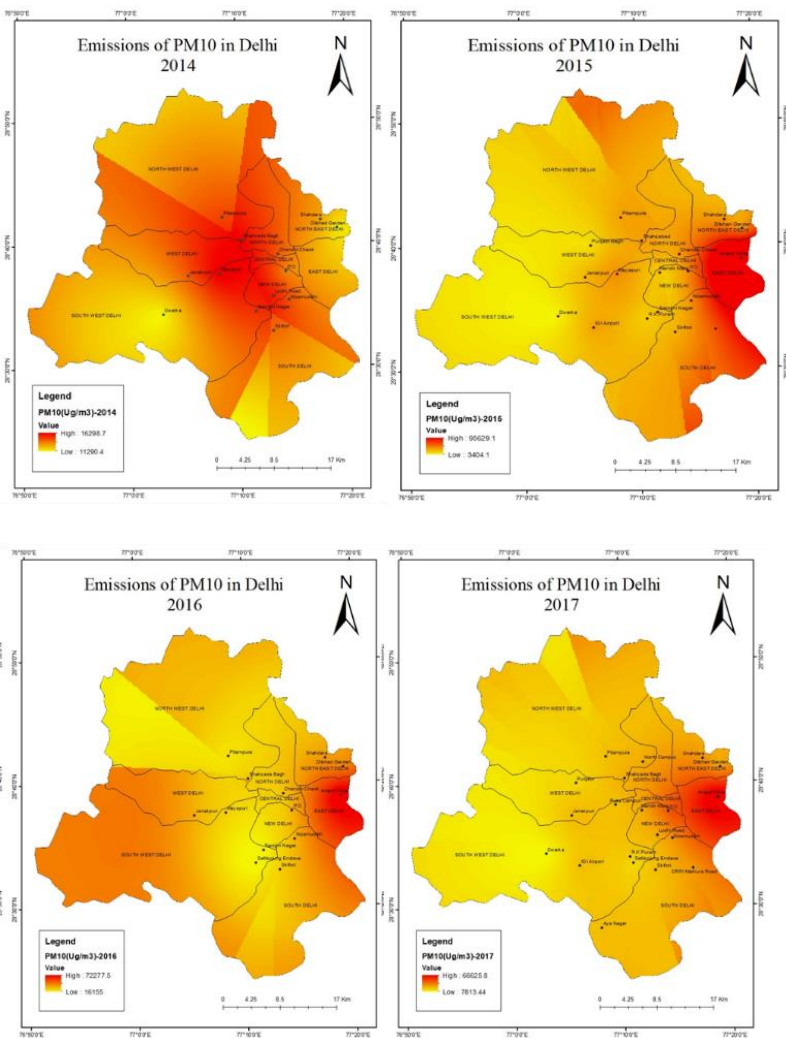

Figure 6: Trends of $\mathrm{PM}_{10}$ in Delhi

So, Aerosols Parameters were used to understand various events in order to ascertain the reasons of high levels of pollution in Delhi. These Parameters are Aerosols Optical Depth (AOD), Angstrom Exponent (AE) and Single Scattering Albedo (SSA). AOD is extinction of sunlight by dust and haze. More the depth means more the hazy conditions, hence pollution in atmosphere. $\mathrm{AE}$ is a qualitative indicator about the turbidity of the atmosphere. High AE indicates fine particles and low for coarse particles. SSA is the ratio of scattering efficiency. If this efficiency increases with increasing wavelengths, it indicates the source of pollution coming from Dust storms, otherwise it is sourced to urban-industrial aerosols or biomass burning.

The highlighted red circles (Figure 7) indicate the rice-residue burning months and which shows direct relation with high AOD in Delhi.

The study for other Aerosol parameters like SSA and AE was done to validate the multiple weather events that occurred in Delhi causing high level of pollution.

\section{EVENT 1: TEHRAN DUST STORM}

In the first week of June, 2014 a dust storm occurred in Tehran, Iran. The AOD was high in Delhi in the succeeding days, AE was low (figure 8) and SSA (figure 9) was overlapping in increasing wavelengths. This indicates that pollution in Delhi was caused by the coarse particles. The PM10 was also high. Hence, the pollution persisting at that time in Delhi can be attributed to the Tehran dust storm. This was further validated by checking the backward trajectory from Delhi from NOAA HYSPLIT Model(figure 10).

\section{EVENT 2: RAJASTHAN STORM}

In the month of May, 2015, a similar phenomenon was there. The AOD was more, as highlighted under Event 2 of figure 7, AE was less (figure 8) meaning coarse particles and again SSA can be seen slightly overlapping by increasing wavelength (figure 9). Again, it could be the phenomenon of the dust storm. This time it came from Rajasthan. The intensity was not that much, hence the magnitude of these graphs of AOD, SSA, and $\mathrm{AE}$ can be seen ascending and descending in a gradual manner. From the auxiliary data given in figure 11, the temperature can be seen high and wind direction can be seen towards north, which is responsible to uplift the pollutants and dispense to Delhi.

\section{EVENT 3: COLD TEMPERATURE AND DIWALI IN DELHI}

In 2016, with the number of high fire counts (figure 3), the festival of Diwali and the cold temperature made Delhi highly pollutant. High levels of $\mathrm{SO}_{2}$ after Diwali caused dense smog in Delhi. High average AOD levels (figure 4), sharply declining AE (figure 8) and highly overlapping SSA (figure 9) indicates that the climatic conditions of Delhi with low temperature and almost no wind speed (figure 12) made it difficult for pollutants to rise and clear the high levels of pollution.

\section{EVENT 4: DUST STORM FROM GULF COUNTRIES}

In 2017, there were multiple dust storms from the gulf countries. In addition, the great smog condition was there. The figure 13 shows one of the many dust storms that hit Delhi in 2017. We can see from figure 4, the AOD levels in October 2017 are high, AE (figure 8) dipped but not too much, which means the storms brought finer particles with it. The SSA overlapped because of the coarse particles but at the same time, in the month of October, there was biomass burning as well, so again towards the end of the year, the SSA starts to increase slightly with increasing wavelengths (figure 9). To validate this event, the backward trajectory from NOAA HYSPLIT Model for that particular day was extracted, as shown in figure 13.

\section{CONCLUSIONS}

This study was focused to enhance scientific knowledge for assessing the role of air pollutant emissions from open burning of rice residue in the state of Punjab and Haryana and their impact on Delhi using various Aerosol parameters and auxiliary data to validate the findings. It was concluded that Fire Counts and increasing pollution levels in Delhi have positive relation. $\mathrm{SO}_{2}$ levels increased rapidly in 2016 and then slowly declined; however, RK Puram received the maximum $\mathrm{SO}_{2}$ emissions of $30 \mu \mathrm{g} / \mathrm{m} 3$ in 2017, according to the CPCB data. Average $\mathrm{NO}_{2}$ Levels increased from $126.8 \mu \mathrm{g} / \mathrm{m} 3$ in 2014 to $157 \mu \mathrm{g} / \mathrm{m} 3$ in 2017. The highest $\mathrm{NO}_{2}$ emissions received in Anand Vihar i.e. $88 \mu \mathrm{g} / \mathrm{m}^{3}$ in 2017 . The main reason was due to the increase in 
the number of vehicles every year in the city. The new engines burn the fuel less but at high temperature, which causes more $\mathrm{NO}_{2} . \mathrm{PM}_{10}$ emissions in 2016 was highest because the smog conditions at the time of Diwali and cold weather conditions did not let the particles dispense anywhere else. In addition, in the year 2017, the levels $\mathrm{PM}_{10}$ decreased but not much because of the cold weather and a great smog event occurred in last week of December. Apart from this, various events were identified using AOD, AE and SSA to understand the situation in Delhi in which Wind trajectories, Meteogram of Temperature, Wind Speed, Wind Direction over Delhi and its neighbouring states were also seen. Increasing population, Motor Vehicles, dust storms, biomass burning were found to be the major contributors of high pollution levels in Delhi.

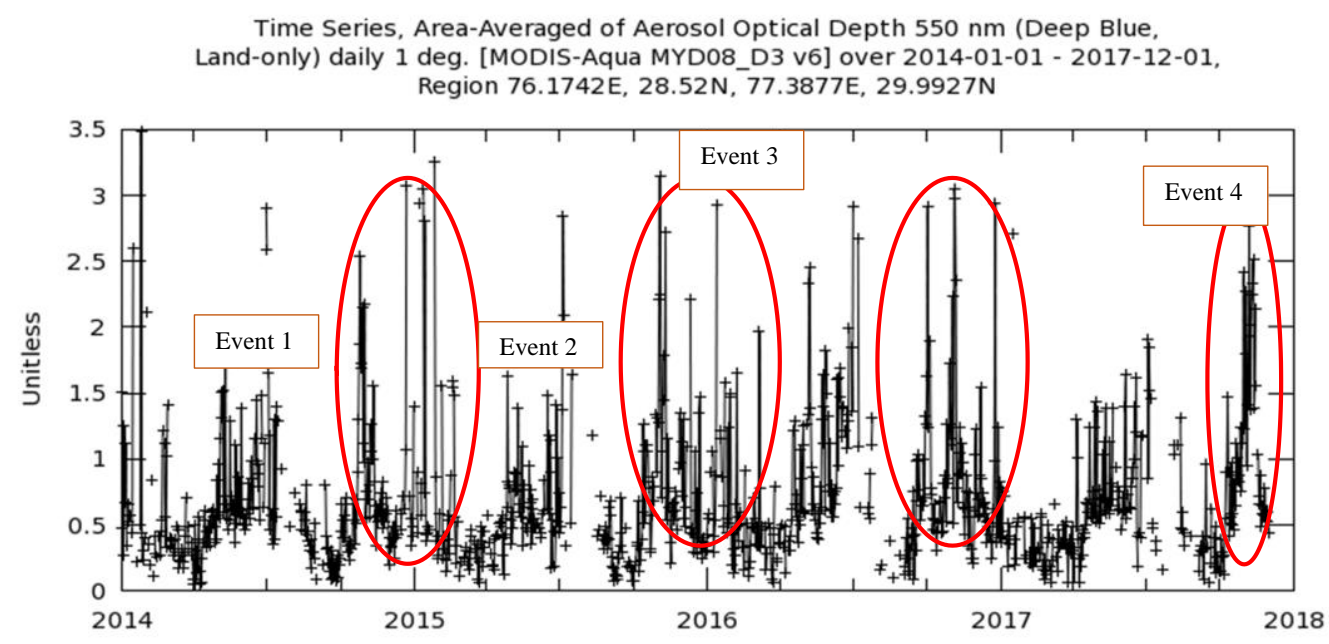

Figure 7: Aerosol Optical Depth of Delhi at 550nm

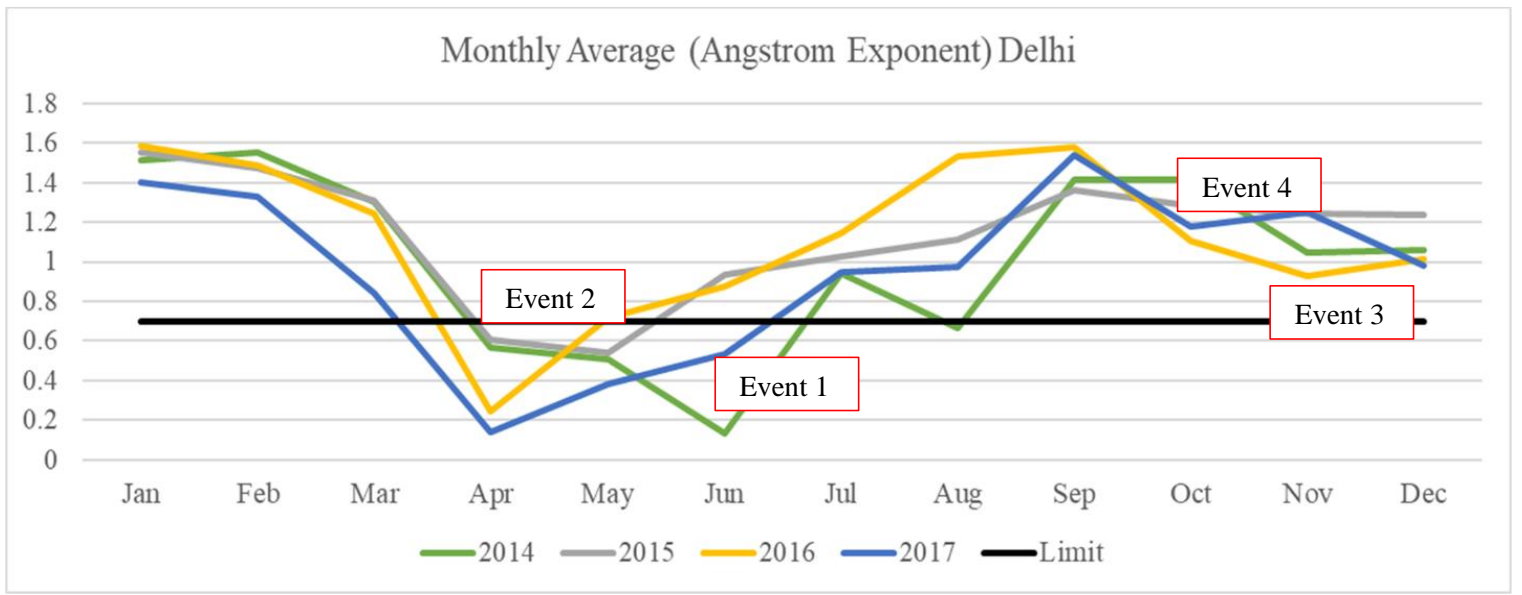

Figure 8: Average Angstrom Exponent of Delhi

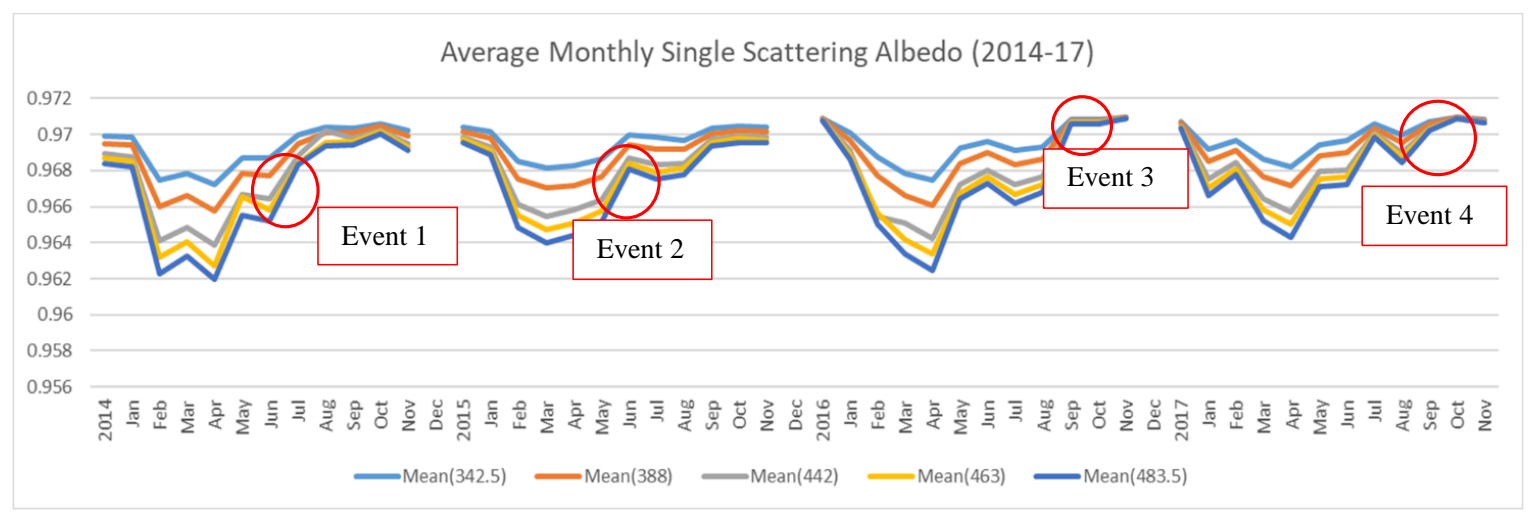

Figure 9: Average Single Scattering Albedo for Delhi 


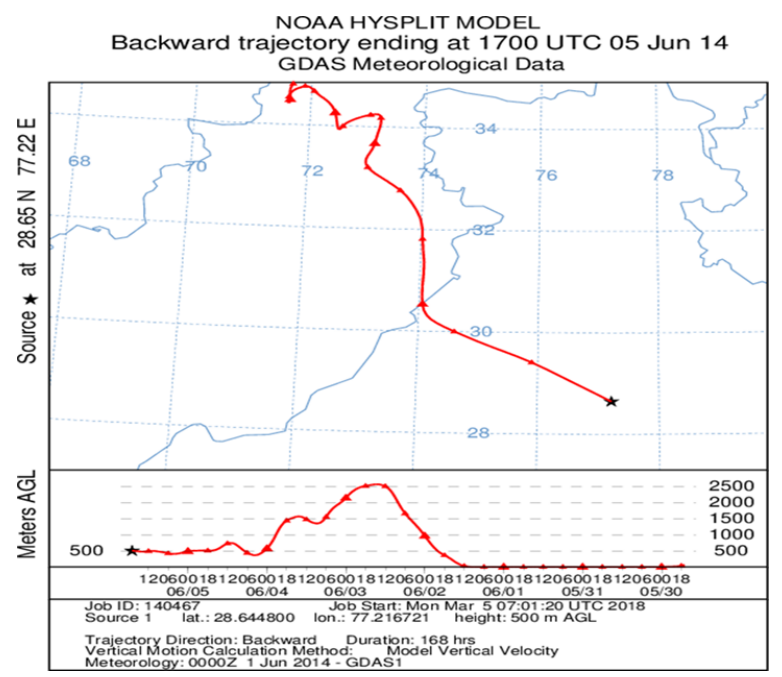

Figure 10: Backward Wind Trajectory, June 2014
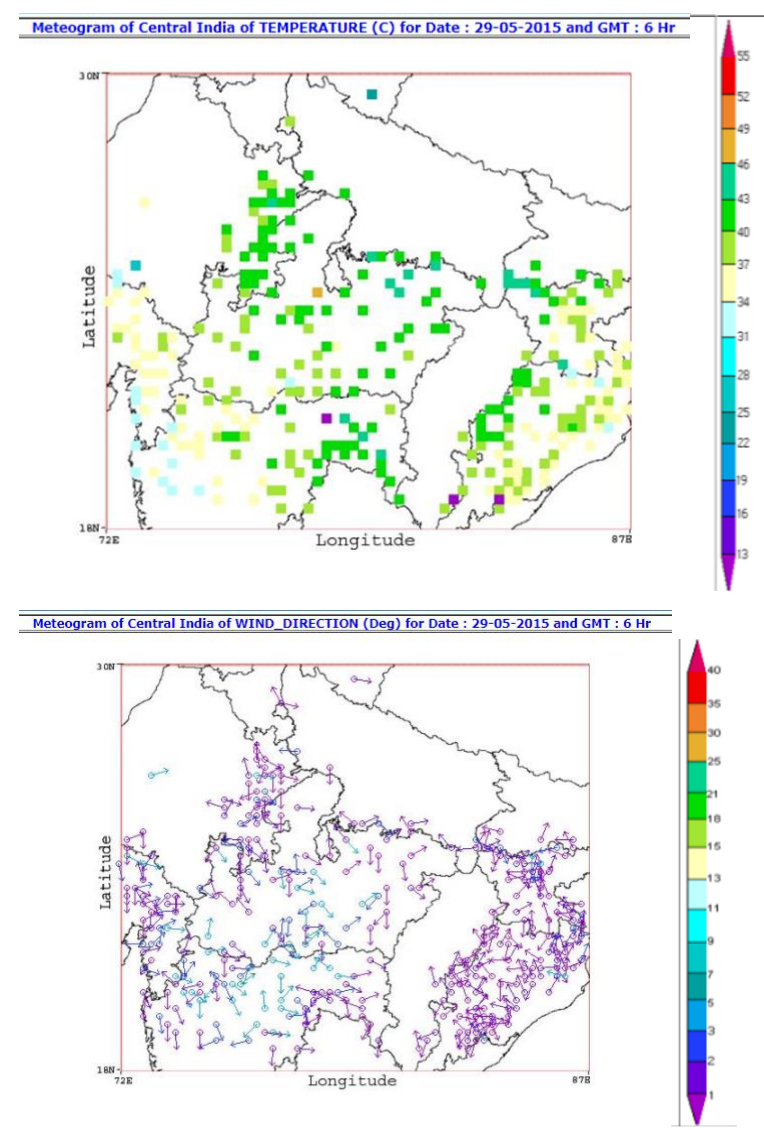

Figure 11: Temperature and Wind direction, May, 2015

\section{Acknowledgements}

The study was conducted as part of the M.Sc. Dissertation of the first author. The first author is thankful to the Mahalanobis National Crop Forecast Centre, for providing her facility to carry out dissertation work. The authors are thankful to Dr. Butchaiah Gadde, UNDP who constantly helped the first author via mails to understand the technical aspects and providing the foundation of the project. The first author also thanks Dr. Disha Sharma for giving her valuable ideas and shaping the project in a better manner.
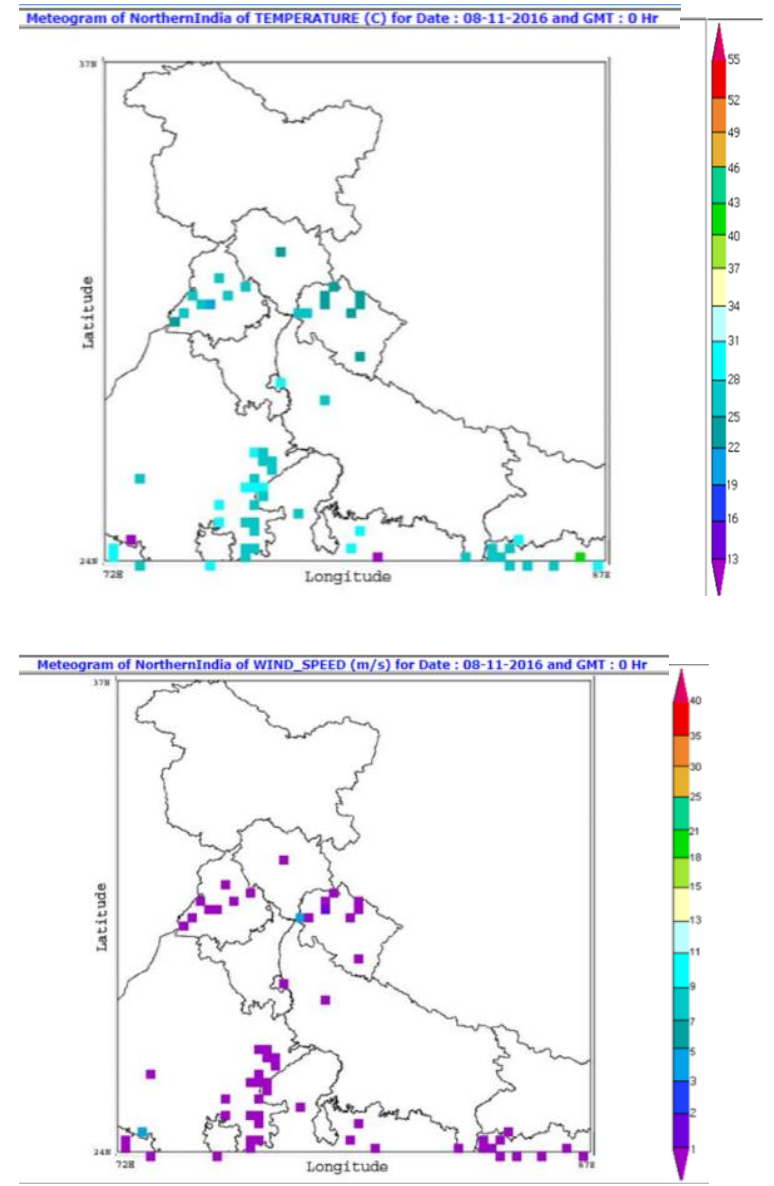

Figure 12: Temperature and Wind Speed, November, 2016

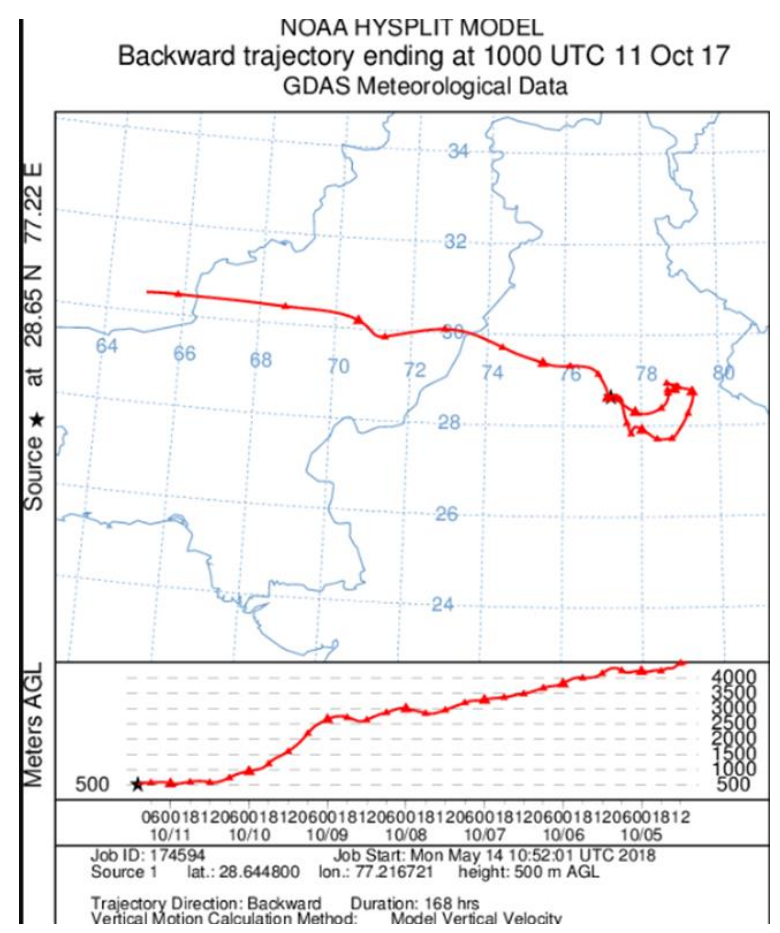

Figure 13: Backward Wind Trajectory, October 2017

\section{References}

Aalde, H. et al. 2006. IPCC Guidelines for National Greenhouse Gas Inventories. Chapter 2: Generic Methodologies Applicable to Multiple Land-Use Categories. 59p. 
Andreae, M. O. and Merlet, P.2001. Emission of trace gases and aerosols from biomass burning, Global Biogeochem. Cycle. 15(4): 955-966.

Gadde B. 2009. Air Pollutant emissions from rice straw open field burning in India, Thailand and the Philippines. Environmental Pollution. 157 (5): 1554-1558

Gupta P.K., Sahai S., Singh N., Dixit C.K., Singh D.P., Sharma C. 2004. Residue burning in rice-wheat cropping system: Causes and implications. Current Science. 87:1713-1715

Jain, Varunika, Saxena, Shalini, Dubey, Sunil, Choudhary, Karan, Sehgal, Seema, Neetu and Ray, S. S. 2019. Rice (Kharif) Production Estimation Using SAR Data of Different Satellites and Yield Models: A Comparative Analysis of The Estimates Generated under FASAL Project. The International Archives of the Photogrammetry, Remote Sensing and Spatial Information Sciences, Volume XLII-3/W6, 2019. pp. 99-107.

Kaskaotis, D.G. et al. 2014. Effects of crop residue burning on aerosol properties, plume characteristics, and long-range transport over northern India. Journal of Geophysical Research: Atmospheres. 119:5424-5444

Montilla, E. Mogo, S. Cachorro, V. Lopez J.and de Frutos, A. 2011. Absorption, scattering and single scattering albedo of aerosols obtained from in situ measurements in the subarctic coastal region of Norway. Atmospheric Chemistry and Physics Discussions. 11: 2161-2182

Ramanathan V., Crutzen, P., Kiehl, J., and Rosenfeld, D. 2001. Aerosols, climate, and the hydrological cycle. Science, 294: 2119-2124.

Ray, S. S. and Neetu. 2017. Crop area estimation with Remote Sensing. In: J. Delincé (ed.), Handbook on Remote Sensing for Agricultural Statistics (Chapter 5). Global Strategy Improving Agricultural and Rural Statistics (GSARS), FAO Statistics Division (ESS), FAO, Rome. pp. 131-183.

Sharma, Disha and Kulshrestha, U. C. 2014. Spatial and Temporal patterns of air pollutants in rural and urban areas of India. Environ Pollut. 195:276-81.

Sidhu, B. S., Rupela, O. P., Beri, V. and Joshi, P. K. 1998. Sustainability Implications of Burning Rice- and Wheat-Straw in Punjab. Economic and Political Weekly. 33 (39): A163A168.

Stein, A. F., Draxler, R. R., Rolph, G. D., Stunder, B. J. B., Cohen, M. D., and Ngan, F. 2015. NOAA's HYSPLIT Atmospheric Transport and Dispersion Modeling System. Bulletin American Meteorological Society. https://doi.org/10.1175/BAMS-D-14-00110.1 